\title{
Características Anatômicas da Lâmina Foliar e do Colmo de Gramíneas Forrageiras Tropicais, em Função do Nível de Inserção no Perfilho, da Idade e da Estação de Crescimento 1
}

\section{Domingos Sávio Campos Paciullo², José Alberto Gomide ${ }^{3}$, Eldo Antônio Monteiro da Silva ${ }^{4}$, Domingos Sávio Queiroz $^{5}$, Carlos Augusto Miranda Gomide ${ }^{6}$}

\begin{abstract}
RESUMO - Foram avaliados os efeitos da idade, do nível de inserção da folha no perfilho e da estação de crescimento (verão ou outono), sobre a proporção de tecidos e a espessura da parede celular em lâminas foliares e segmentos de colmo de capim-braquiária (Brachiaria decumbens), capim-gordura (Melinis minutiflora) e capim-tifton 85 (Cynodon sp). Lâminas foliares das posições inferior e superior do perfilho foram colhidas no dia da exposição da lígula e 20 dias após. Foram determinadas as proporções relativas de epiderme, xilema, floema, bainha parenquimática dos feixes, esclerênquima, parênquima no colmo e mesofilo na lâmina foliar. Foram medidas as espessuras das paredes dos vasos de metaxilema e do esclerênquima da lâmina e do colmo. A proporção de tecidos em lâminas foliares não foi alterada pela idade nem pela estação de crescimento, sendo a espessura da parede de células do esclerênquima da lâmina a única característica modificada pela idade. Lâminas do nível de inserção superior apresentaram mais elevadas proporções de esclerênquima, bainha parenquimática dos feixes e xilema e células do esclerênquima e do metaxilema com paredes mais espessas, enquanto as lâminas do nível de inserção inferior se destacaram por apresentar mais elevada proporção de mesofilo e paredes celulares mais delgadas. Enquanto a proporção de parênquima decresceu, a área relativa de esclerênquima e as espessuras das paredes celulares variaram diretamente com a idade do colmo e foram maiores, em geral, no verão.
\end{abstract}

Palavras-chave: anatomia, Brachiaria decumbens, Cynodon spp, espessura da parede celular, Melinis minutiflora, proporção de tecidos

\section{Anatomical Traits of Leaf Blade and Stem of Tropical Forage Grasses, According to Level of Insertion on the Grass Tiller, Age and Season of Growth}

\begin{abstract}
An experiment was carried out to evaluate the effect of leaf age and insertion level and season of growth on the tissue proportion and the cell wall thickness of leaf blade and stem segment of signalgrass (Brachiaria decumbens), molassesgrass (Melinis minutiflora) and Tifton 85 bermudagrass (Cynodon $s p$ ). Leaf blades from bottom and top layers were sampled on the day of ligule exposure and 20 days later. The relative proportion of epidermis, xylem, phloem, parenchyma bundle sheath, sclerenchyma, stem parenchyma and leaf blade mesophyll were estimated. The thickness of cell wall of metaxylem vessels and sclerenchyma were evaluated. Leaf tissue proportion changed neither with age nor season of growth; thickness of leaf sclerenchyma cell wall was the only trait to change with age. Leaf from the top layer showed higher proportion of sclerenchyma, parenchyma bundle sheath and xylem as well as thicker cell wall in sclerenchyma and metaxylem; while leaves from the bottom layer had higher proportion of mesophyll and thinner sclerenchyma and metaxylem cell walls. While the parenchyma proportion of the stem decreased, the relative area of the sclerenchyma and the cell wall thickness increased as the plant aged. These traits showed greater values in summer samples.
\end{abstract}

Key Words: anatomy, Brachiaria decumbens, Cynodon spp, cell wall thickness, Melinis minutiflora, tissue proportion

\section{Introdução}

A anatomia da folha influencia não só a produção de forragem, mas também seu valor nutritivo e o desempenho animal. Os tecidos vegetais apresentam potenciais de digestão diferenciados, do que decorre a associação entre a proporção de tecidos, medida em seções transversais de folhas e colmos, e o valor nutritivo de gramíneas forrageiras (Wilkins, 1972; Wilson, 1976b; Queiroz et al., 2000). Em geral, as células do mesofilo e as do floema, de delgada parede celular, são rapidamente digeridas (Akin et al., 1973; Chesson et al., 1986), as da epiderme e da bainha parenquimática dos feixes são de digestão lenta e

\footnotetext{
${ }_{1}^{1}$ Parte da tese de Doutorado do $1^{\circ}$ autor apresentada à UFV.

${ }^{2}$ Bolsista de Recém-Doutor do CNPq - Embrapa Gado de Leite. E.mail: dscp@terra.com.br

${ }^{3}$ Pesquisador IA do CNPq. Departamento de Zootecnia - UFV. Viçosa - MG.

${ }^{4}$ Professor do Departamento de Biologia Vegetal - UFV. Viçosa - MG.

${ }^{5}$ Pesquisador da EPAMIG - UFV. Viçosa - MG.

${ }^{6}$ Bolsista de Pós-doutorado da FAPESP - UNESP - Jaboticabal - SP.
} 
parcial (Akin, 1989) e o esclerênquima e o xilema, que apresentam parede celular espessa e lignificada, são muito pouco digeridos (Akin, 1989; Wilson, 1993).

A estrutura anatômica de gramíneas do tipo C4, caracterizada por elevadas proporções de feixes vasculares, esclerênquima e bainha parenquimática dos feixes, compromete o valor nutritivo destas plantas (Wilson, 1997).

A quantificação da área ocupada pelos tecidos em uma seção transversal, apesar de bom indicativo do valor nutricional, ignora diferenças de composição química e espessura da parede celular, o que limita o valor da proporção de tecidos como indicador do valor nutritivo (Wilson, 1993). Assim, medidas da espessura da parede das células de determinados tecidos podem complementar as informações da proporção de tecidos.

Diferenças anatômicas entre lâminas foliares de diferentes níveis de inserção no perfilho têm recebido pouca atenção em trabalhos científicos. Além disso, nota-se, em alguns estudos, confundimento do efeito do nível de inserção com o da idade cronológica da folha, porque folhas de diferentes níveis de inserção diferem em idade. Wilson (1976b) mostrou que lâminas foliares de mais alto nível de inserção apresentaram maior proporção de esclerênquima e xilema, paredes celulares mais espessas e menor quantidade de mesofilo que lâminas localizadas na base do perfilho. $\mathrm{O}$ aumento da idade da folha de um mesmo nível de inserção não alterou a proporção dos diferentes tecidos, apesar de resultar em aumento da espessura da parede das células do esclerênquima, prin- cipalmente em bainhas foliares situadas na posição superior do perfilho.

A diversidade de gramíneas forrageiras presentes nas pastagens brasileiras e o desconhecimento quase total de suas características anatômicas relacionadas ao valor nutritivo conferem grande importância aos estudos da anatomia e da digestão dos diferentes tecidos.

O objetivo desse trabalho foi avaliar o efeito do nível de inserção e da estação do ano sobre as características anatômicas de lâminas foliares de gramíneas forrageiras e o efeito da idade sobre a anatomia da lâmina e do colmo.

\section{Material e Métodos}

As gramíneas forrageiras capim-gordura (Melinis minutiflora), capim-tifton 85 (Cynodon sp) e capimbraquiária (Brachiaria decumbens) foram cultivadas em área do Departamento de Zootecnia da Universidade Federal de Viçosa, em Viçosa, Minas Gerais. Viçosa localiza-se a $20^{\circ} 45^{\prime}$ de latitude sul e $42^{\circ} 54^{\prime}$ de latitude oeste, a uma altitude média de $650 \mathrm{~m}$. Seu clima é do tipo Cwb (classificação Köppen), clima tropical de altitude, com verões quentes e chuvosos. As principais variáveis climáticas predominantes durante a fase de avaliação do experimento são apresentadas na Tabela 1.

As gramíneas foram plantadas em novembro de 1996, em parcelas de $20 \mathrm{~m}^{2}$, sendo o experimento iniciado em dezembro de 1998. Após corte de uniformização, realizado com cutelo, a altura de $5 \mathrm{~cm}$ acima do solo, foi feita adubação em cobertura com sulfato de

Tabela 1 - Variáveis climáticas observadas durante o período experimental

Table 1 - Climatic variables observed during the experimental period

\begin{tabular}{lccc}
\hline $\begin{array}{l}\text { Mês/ano } \\
\text { Month/year }\end{array}$ & $\begin{array}{c}\text { Precipitação total }(\mathrm{mm}) \\
\text { Total rainfall }(\mathrm{mm})\end{array}$ & $\begin{array}{c}\text { Temperatura máx. média }\left({ }^{\circ} \mathrm{C}\right) \\
\text { Maximum average temperature }\left({ }^{\circ} \mathrm{C}\right)\end{array}$ & $\begin{array}{c}\text { Temperatura min. média } \\
\text { Minimum average temperature }\end{array}$ \\
\hline $\begin{array}{l}\text { Dezembro/98 } \\
\text { December/98 }\end{array}$ & 105,3 & 28,9 & 18,3 \\
Janeiro/99 & 154,2 & 30,3 & 18,9 \\
$\begin{array}{l}\text { January/99 } \\
\text { Fevereiro/99 }\end{array}$ & 88,1 & 29,9 & 18,4 \\
$\begin{array}{l}\text { February/99 } \\
\text { Março/99 }\end{array}$ & 273,7 & 28,5 & 17,8 \\
$\begin{array}{l}\text { March/99 } \\
\text { Abril/99 }\end{array}$ & 36,5 & 27,6 & 16,1 \\
$\begin{array}{l}\text { April/99 } \\
\text { Maio/99 }\end{array}$ & 2,0 & 25,3 & 12,1 \\
$\begin{array}{l}\text { May/99 } \\
\text { Junho/99 }\end{array}$ & 13,2 & 21,8 & 11,5 \\
June/99 & & &
\end{tabular}


amônio (60 kg/ha de $\mathrm{N})$, cloreto de potássio $(60 \mathrm{~kg} / \mathrm{ha}$ de $\left.\mathrm{K}_{2} \mathrm{O}\right)$ e superfosfato simples $\left(80 \mathrm{~kg} / \mathrm{ha}\right.$ de $\left.\mathrm{P}_{2} \mathrm{O}_{5}\right)$.

Foram selecionados e identificados com anéis de mesma coloração quatro grupos de 10 perfilhos em cada parcela. O critério para orientar a colheita dos perfilhos baseou-se no nível de inserção e na idade da folha. Os perfilhos foram vistoriados periodicamente para se determinar o momento da colheita. No primeiro grupo de dez perfilhos coletou-se a $3^{\text {a }}$ folha, da base para o topo, do perfilho de capim-braquiária e capimgordura e a $4^{\mathrm{a}}$ folha de capim-tifton 85 (folhas de nível de inserção inferior), no momento da completa expansão (idade 0), caracterizado pelo aparecimento da lígula. No segundo grupo de perfilhos, foram retiradas folhas do nível de inserção inferior, porém 20 dias após o aparecimento da lígula (idade 20). No terceiro grupo de perfilhos, coletou-se a $7^{\text {a }}$ folha de capim-braquiária e capim-gordura e a $11^{\text {a }}$ de capim-tifton 85 (folhas de nível de inserção superior) na idade 0 . No quarto grupo de perfilhos, amostraram-se folhas na idade 20 e situadas no nível de inserção superior. A colheita de cada grupo de perfilhos foi realizada em um mesmo dia para as três espécies.

Foi amostrado apenas o segmento de colmo localizado imediatamente abaixo da folha de nível de inserção superior, tendo em vista que, no momento da colheita da folha de nível de inserção inferior, o colmo não havia sido formado, existindo apenas pseudocolmo. No momento da colheita, os segmentos de colmo apresentavam seus tecidos diferenciados. Por isso, aqueles associados às folhas recém-expandidas foram chamados de colmos jovens e os associados às folhas com 20 dias de idade foram chamados de colmos em idade avançada.

Foram realizadas avaliações em duas estações de crescimento, visando identificar os possíveis efeitos dos fatores climáticos sobre as características avaliadas. Nos meses de dezembro/98 e janeiro/99 foram amostrados os perfilhos do crescimento de verão. No final do mês de março as plantas foram novamente cortadas e adubadas (mesmos níveis aplicados para o crescimento de verão). Nos meses de maio e junho de 1999, colheram-se amostras de perfilhos do crescimento de outono (Tabela 2).

Foram realizadas irrigações na área experimental sempre que se observava período de uma semana sem chuva.

As avaliações anatômicas foram desenvolvidas no laboratório de Anatomia, pertencente ao Departamento de Biologia Vegetal da UFV.
No momento pré-determinado (dia do aparecimento da lígula ou 20 dias após o aparecimento da lígula), os perfilhos foram colhidos para a obtenção das lâminas foliares e dos segmentos de colmo de interesse às análises anatômicas. De uma porção mediana da lâmina e do segmento de colmo amostrados, foi retirado um fragmento de aproximadamente $1 \mathrm{~cm}$, que foi colocado em fixador FAA 50 (formol a 40\%, álcool a 50\% e ácido acético glacial), em uma proporção aproximada, volume do fixador/ volume de tecido vegetal, de 20 a 30 vezes.

Três fragmentos de cada fração (lâmina foliar e colmo) foram submetidos à série alcoólica progressiva para desidratação. Após inclusão em "paraplast", os fragmentos foram seccionados transversalmente a $10 \mu \mathrm{m}$, com uso de micrótomo rotatório, desparafinizados, efetuando-se a coloração quádrupla triarca dos tecidos (Hagquist, 1974) e a montagem de lâminas permanentes.

A avaliação da contribuição de cada tecido para a área total da seção foi realizada em uma área entre dois feixes vasculares maiores, incluindo um deles, localizada na porção mediana entre a nervura principal e a margem da lâmina foliar. No colmo, foi avaliada uma região entre o centro e a epiderme. A mensuração dos tecidos foi feita com auxílio do microscópio de luz e do Software de Análise de Imagens, modelo Image Pro Plus versão 1.3. Na lâmina foliar, foram medidas as áreas das epidermes (EPI) (adaxial e abaxial), do esclerênquima (ESC), da bainha parenquimática dos feixes vasculares (BPF),

Tabela 2 - Datas de colheitas dos perfilhos, de acordo com a idade da folha e seu nível de inserção no perfilho

Table 2 - Dates of harvests of tillers, according to leaf age and level of insertion on grass tiller

\begin{tabular}{lcc}
\hline $\begin{array}{l}\text { Nível de inserção } \\
\text { Level of insertion }\end{array}$ & $\begin{array}{c}\text { Idade (Dias) } \\
\text { Age (Days) }\end{array}$ & $\begin{array}{c}\text { Data da colheita } \\
\text { Date of harvest }\end{array}$ \\
\hline \multicolumn{2}{c}{ Verão } \\
Summer \\
Inferior & 0 & $20 / 12 / 1998$ \\
Lower & 20 & $09 / 01 / 1999$ \\
Superior & 0 & $10 / 01 / 1999$ \\
Upper & 20 & $30 / 01 / 1999$ \\
& \multicolumn{3}{c}{ Outono } \\
Inferior & 0 & Autumn \\
Lower & 20 & $03 / 05 / 1999$ \\
Superior & 0 & $23 / 05 / 1999$ \\
Upper & 20 & $30 / 05 / 1999$ \\
& \multicolumn{3}{c}{$19 / 06 / 1999$} \\
\hline
\end{tabular}


do xilema mais fibras associadas (XIL) e do floema (FLO). A região do mesofilo (MES) (parênquima clorofiliano) foi calculada pela diferença entre a área total da seção transversal e as áreas dos demais tecidos. No colmo, foram mensuradas as áreas da EPI, XIL, FLO, ESC e parênquima (PAR). Na Figura 1, são mostradas seções transversais da lâmina foliar e do colmo, com indicação dos tecidos avaliados.

Avaliações da espessura da parede das células do ESC e dos vasos de metaxilema (MET) na lâmina e no colmo foram realizadas em 20 células, por repetição. Foram medidas as paredes das células de ESC, associadas aos feixes vasculares maiores, na lâmina foliar, e aquelas situadas entre dois feixes, no colmo. Os vasos de MET foram medidos nos feixes vasculares maiores.
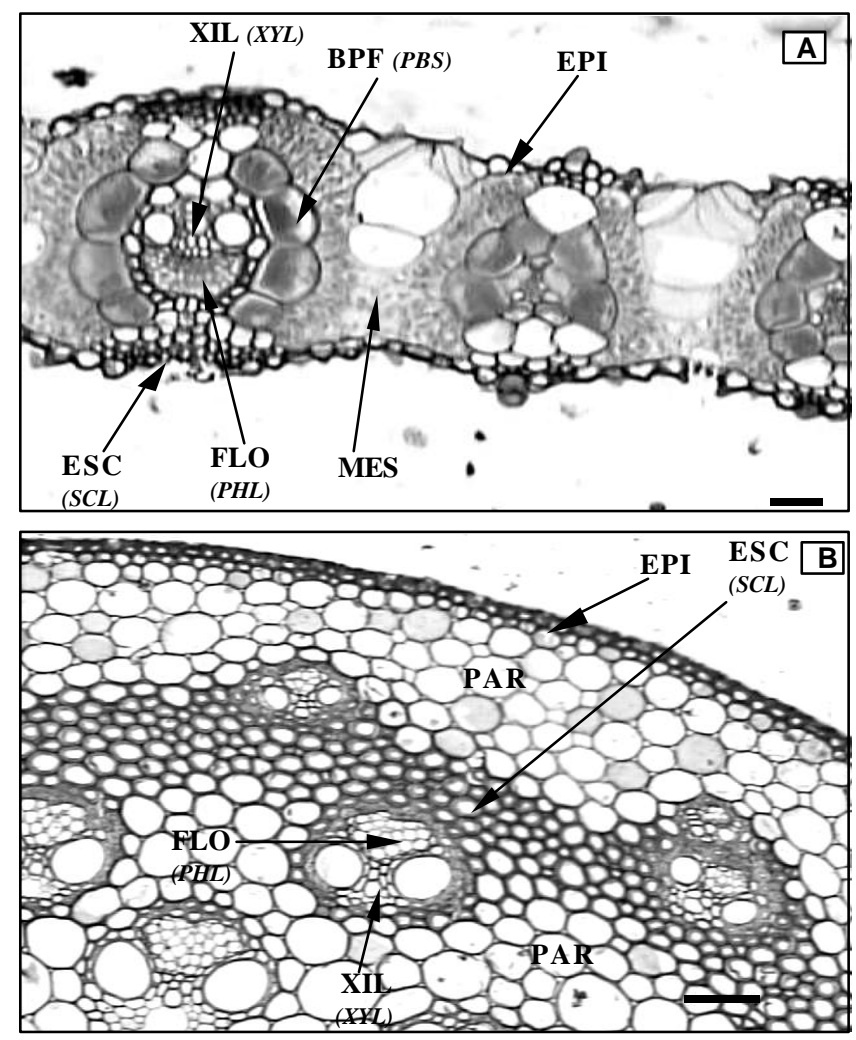

Figura 1 -Seções transversais de lâmina foliar de capim-tifton 85 (A) e de colmo de capim braquiária (B). EPI - epiderme, ESC esclerênquima, BPF - bainha parenquimática dos feixes, MES - mesofilo, PAR - parênquima, XIL - xilema e FLO - floema. (A $25 \mu \mathrm{m}$ e $\mathrm{B}-50 \mu \mathrm{m}$ ).

Figure 1 - Transversal sections of leaf blade of bermudagrass tifton 85 (A) and signalgrass stem (B). EPI epidermis, $S C L$-sclerenchyma, $P B S$ - parenchyma bundle sheath, MES - mesophyll, PAR - parenchyma, $X Y L-x y l e m$ and $P H L-$ phloem. (A $25 \mu \mathrm{m}$ and $B=50 \mu \mathrm{m}$ ).

R. Bras. Zootec., v.31, n.2, p.890-899, 2002 (suplemento)
$\mathrm{O}$ registro das imagens foi realizado copiando-se as imagens armazenadas na memória do computador para um disco flexível de 3,5".

Os resultados referentes à proporção de tecidos e espessura da parede celular foram submetidos à análise de variância, utilizando-se o programa SAEG - Sistema de Análises Estatísticas e Genéticas (Universidade Federal de Viçosa - UFV, 1995), para verificação dos efeitos da espécie, da idade e da estação de crescimento, para as lâminas foliares e os colmos, além do efeito do nível de inserção no perfilho, para as lâminas, apenas.

As interações significativas foram desdobradas e as médias, comparadas pelo teste de Tukey a 5\% de probabilidade.

\section{Resultados e Discussão}

A proporção de EPI do colmo, que foi de $2,8 \%$ da seção transversal, não variou com os fatores estudados.

O efeito de estação sobre as proporções de XIL e FLO não foi consistente (Tabela 3). Assim, maiores proporções foram observadas no verão, para o capim-tifton 85, e no outono, para o capim-gordura, enquanto, em capim-braquiária, as proporções de XIL e FLO não variaram com a estação do ano. Em qualquer das estações, o capim-gordura apresentou maiores proporções de XIL e FLO.

A proporção de $\mathrm{PAR}$ variou $(\mathrm{P}<0,01)$ inversamente com a idade do colmo, em capim-gordura, e não foi influenciada $(\mathrm{P}<0,05)$ pela estação do ano, senão em capim-tifton 85 , em que maior proporção foi observada no outono (Tabela 4). Por outro lado, a área relativa de ESC aumentou $(\mathrm{P}<0,05)$ com $\mathrm{o}$ avanço da idade e foi maior, em geral, na estação do verão (Tabela 5). O colmo de capim-gordura exibiu a mais baixa proporção de ESC, quando jovem, e a mais alta, quando em idade mais avançada.

O aumento da proporção de ESC, com o avanço da idade, pode ser atribuído às alterações sofridas pelas células parenquimáticas durante o desenvolvimento do colmo. Colmos jovens são altamente digestíveis (Hackher \& Minson, 1981), mas, com o desenvolvimento, parte das células parenquimáticas apresenta progressivo espessamento e lignificação da parede, formando um rígido e indigestível anel de células esclerenquimáticas. Este comportamento está relacionado à intensa redução na digestibilidade de colmos, com o avançar da idade. 
Tabela 3 - Proporção de xilema (XIL) e floema (FLO) (\% da seção transversal) em fragmentos de colmo, conforme a espécie e a estação de crescimento

Table 3 - Xylem (XYL) and phloem (PHL) proportion (\% of transversal section) in stem fragments, according to species and season of growth

\begin{tabular}{lcc}
\hline $\begin{array}{l}\text { Espécie } \\
\text { Species }\end{array}$ & \multicolumn{2}{c}{$\begin{array}{c}\text { Estação de crescimento } \\
\text { Season of growth }\end{array}$} \\
\cline { 2 - 3 } & $\begin{array}{c}\text { Verão } \\
\text { Summer }\end{array}$ & $\begin{array}{c}\text { Outono } \\
\text { Autumn }\end{array}$ \\
\hline & \multicolumn{2}{c}{ XIL $(X Y L)$} \\
Capim-braquiária & $15,6^{\mathrm{Ba}}$ & $16,7^{\mathrm{Ba}}$ \\
$\begin{array}{l}\text { Signalgrass } \\
\text { Capim-gordura }\end{array}$ & $24,8^{\mathrm{Ab}}$ & $27,6^{\mathrm{Aa}}$ \\
$\begin{array}{l}\text { Molassesgrass } \\
\text { Capim-tifton } 85\end{array}$ & $15,2^{\mathrm{Ba}}$ & $12,5^{\mathrm{Cb}}$ \\
Bermudagrass & &
\end{tabular}

Bermudagrass tifton 85

$\begin{array}{lcc}\text { Capim-braquiária } & 3,4^{\mathrm{Ba}} & 3,7^{\mathrm{Ba}} \\ \begin{array}{l}\text { Signalgrass } \\ \text { Capim-gordura }\end{array} & 4,2^{\mathrm{Ab}} & 4,8^{\mathrm{Aa}} \\ \begin{array}{l}\text { Molassesgrass } \\ \text { Capim-tifton } 85\end{array} & 3,9^{\mathrm{ABa}} & \\ \text { Bera } & 3,1^{\mathrm{Bb}}\end{array}$

Bermudagrass tifton 85

Médias seguidas de letras diferentes, minúsculas nas linhas e maiúsculas nas colunas, em cada tecido, diferem $(P<0,05)$ pelo teste de Tukey.

Means followed by different letters, small in the row and capital in the column, for each tissue, are different $(P<.05)$ by Tukey test.

Os tecidos resistentes à digestão representaram $28,9 \%$ da seção transversal do segmento de colmo, considerando-se os valores médios das proporções de EPI $(2,8 \%)$, XIL $(18,7 \%)$ e ESC $(7,4 \%)$. A pequena área ocupada por estes tecidos de parede celular espessada e lignificada parece não refletir o efeito negativo que eles exercem sobre a digestão do colmo.
Entretanto, emSorghum bicolor, apesar destes tecidos ocuparem apenas $20 \%$ da área da seção, contribuíram com 50\% do peso seco do entrenó, $75 \%$ do total de parede celular e $67 \%$ da parede celular indigestível, (Wilson et al., 1993). Por outro lado, as células de parênquima, que ocuparam a maior área da seção (80\%), contribuíram com $47 \%$ do peso seco, $21 \%$ do conteúdo de parede celular e $26 \%$ da parede indigestível.

O capim-tifton 85 apresentou, na lâmina foliar, mais alta $(\mathrm{P}<0,05)$ proporção de epiderme adaxial (18,3\% contra 16,1 e $16,8 \%$ da seção transversal de lâminas de capim-gordura e capim-braquiária, respectivamente $)$ e mais baixa $(\mathrm{P}<0,05)$ de epiderme abaxial $(6,9 \%)$ que o capim-braquiária $(9,2 \%)$ e o capim-gordura $(8,8 \%)$, que não diferiram entre si.

À lâmina foliar do capim-gordura correspondeu maior $(\mathrm{P}<0,01)$ proporção de XIL $(6,5 \%)$, que não diferiu entre o capim-tifton 85(5,5\%) e o capim-braquiária $(5,1 \%)$. Por outro lado, o capim-tifton 85 apresentou mais alta $(\mathrm{P}<0,01)$ proporção de FLO $(2,1 \%)$ que as duas outras espécies $(1,1$ e $0,9 \%$, respectivamente para capim-braquiária e capim-gordura).

A proporção de tecidos não variou com a idade, nem com a estação de crescimento, com exceção da mais elevada $(\mathrm{P}<0,05)$ proporção de XIL emlâminas colhidas no verão $(6,4 \%)$, quando comparadas às do outono $(5,1 \%)$.

Os resultados obtidos neste trabalho são consistentes com a literatura, segundo a qual são pequenos e inconsistentes os efeitos da idade e de fatores climáticos sobre a proporção de tecidos de lâminas foliares (Wilson et al., 1991; Paciullo et al., 1999; Queiroz et al., 2000). Por essa razão, decréscimos na digestibilidade de forrageiras, com o aumento da temperatura e o avanço do desenvolvimento, normal-

Tabela 4 - Proporção de parênquima (\% na seção transversal) em fragmentos de colmo, conforme a estação de crescimento, a idade e a espécie

Table 4 - Parenchyma proportion (\% of transversal section) in stem fragments, according to season of growth, age and specie

\begin{tabular}{|c|c|c|c|c|}
\hline \multirow[t]{2}{*}{$\begin{array}{l}\text { Espécie } \\
\text { Specie }\end{array}$} & \multicolumn{2}{|c|}{$\begin{array}{l}\text { Estação de crescimento } \\
\text { Season of growth }\end{array}$} & \multicolumn{2}{|c|}{$\begin{array}{l}\text { Idade } \\
\text { Age }\end{array}$} \\
\hline & $\begin{array}{c}\text { Verão } \\
\text { Summer }\end{array}$ & $\begin{array}{l}\text { Outono } \\
\text { Autumn }\end{array}$ & $\begin{array}{l}\text { Jovem } \\
\text { Young }\end{array}$ & $\begin{array}{c}\text { Avançada } \\
\text { Old } \\
\end{array}$ \\
\hline $\begin{array}{l}\text { Capim-braquiária } \\
\text { Signalgrass }\end{array}$ & $70,9^{\mathrm{Aa}}$ & $69,9^{\mathrm{Ba}}$ & $71,8^{\mathrm{Aa}}$ & $68,9^{\mathrm{Aa}}$ \\
\hline $\begin{array}{l}\text { Capim-gordura } \\
\text { Molassesgrass }\end{array}$ & $61,5^{\mathrm{Ba}}$ & $58,4^{\mathrm{Ca}}$ & $67,8^{\mathrm{Ba}}$ & $52,0^{\mathrm{Bb}}$ \\
\hline $\begin{array}{l}\text { Capim-tifton } 85 \\
\text { Bermudagrass tifton } 85\end{array}$ & $70,0^{\mathrm{Ab}}$ & $74,8^{\mathrm{Aa}}$ & $73,8^{\mathrm{Aa}}$ & $70,9^{A a}$ \\
\hline
\end{tabular}

Médias seguidas de letras diferentes, minúsculas nas linhas comparam estações do ano ou idades e maiúsculas nas colunas, diferem $(\mathrm{P}<0,05)$ pelo teste de Tukey.

Means followed by different letters, small in the row compare seasons of growth or ages, and capital in the column, are different (P<.05) by Tukey test. 
Tabela 5 - Proporção de esclerênquima (\% na seção transversal) em fragmentos de colmo, conforme a estação de crescimento, a idade e a espécie

Table 5 - Sclerenchyma proportion (\% of transversal section) in stem fragments, according to season of growth, age and species

\begin{tabular}{|c|c|c|c|c|c|}
\hline \multirow[t]{2}{*}{$\begin{array}{l}\text { Idade } \\
\text { Age }\end{array}$} & \multicolumn{2}{|c|}{$\begin{array}{l}\text { Estação de crescimento } \\
\text { Season of growth }\end{array}$} & \multicolumn{3}{|c|}{$\begin{array}{l}\text { Espécie } \\
\text { Species }\end{array}$} \\
\hline & $\begin{array}{c}\text { Verão } \\
\text { Summer }\end{array}$ & $\begin{array}{l}\text { Outono } \\
\text { Autumn }\end{array}$ & $\begin{array}{c}\text { Capim-braquiária } \\
\text { Signalgrass }\end{array}$ & $\begin{array}{l}\text { Capim-gordura } \\
\text { Molassesgrass }\end{array}$ & $\begin{array}{c}\text { Capim-tifton } 85 \\
\text { Bermudagrass tifton } 85\end{array}$ \\
\hline $\begin{array}{l}\text { Jovem } \\
\text { Young }\end{array}$ & $4,2^{\mathrm{Ba}}$ & $4,0^{\mathrm{Ba}}$ & $6,3^{\mathrm{Ba}}$ & $2,1^{\mathrm{Bb}}$ & $5,9^{\mathrm{Ba}}$ \\
\hline $\begin{array}{l}\text { Avançada } \\
\text { Old }\end{array}$ & $11,6^{\mathrm{Aa}}$ & $8,7^{\mathrm{Ab}}$ & $8,6^{\mathrm{Ab}}$ & $13,5^{\mathrm{Aa}}$ & $8,1^{\mathrm{Ab}}$ \\
\hline
\end{tabular}

Médias seguidas de letras diferentes, minúsculas nas linhas comparam estações de crescimento ou espécies e maiúsculas nas colunas, diferem $(P<0,05)$ pelo teste de Tukey.

Means followed by different letters, small in the row compare seasons of growth or species, and capital in the column, are different $(P<0,05)$ by Tukey test.

mente citados na literatura, não devem ser atribuídos a alterações na proporção de tecidos da folha. Wilson et al. (1991) apontam a intensa lignificação da parede celular como o principal fator a atuar negativamente na digestibilidade de gramíneas forrageiras que se desenvolvem sob elevadas temperaturas.

A interação nível de inserção $x$ espécie foi significativa $(\mathrm{P}<0,01)$ para a proporção de MES, ESC e BPF (Tabela 6). As proporções de ESC e BPF foram mais altas nas lâminas da posição superior, com exceção da proporção de ESC em capim-braquiária e de BPF em capim-tifton 85. Por outro lado, lâminas da posição inferior apresentaram maior proporção de MES, exceto para o capim-tifton 85, cuja proporção de MES não variou em função de seu nível de inserção. Apesar de não alcançarem significância estatística, as proporções de MES, em capim-tifton 85, e de ESC, em capim-braquiária, mostraram tendências semelhantes às demais espécies com a variação do nível de inserção. Maiores proporções de MES e ESC foram encontradas no capim-tifton 85, independente do nível de inserção.

Lâminas da posição superior do perfilho apresentaram maior $(\mathrm{P}<0,01)$ proporção de XIL, independente da idade, da espécie e da estação do ano.

Foram encontrados valores de 6,3 e 5,0\%, respectivamente, para lâminas das posições superior e inferior do perfilho.

Os resultados mostram mudanças na proporção de tecidos da lâmina foliar, conforme o nível de

Tabela 6 - Proporção de esclerênquima (ESC), bainha parenquimática dos feixes (BPF) e mesofilo (MES) (\% na seção transversal) em lâminas foliares, conforme a espécie e o nível de inserção

Table 6 - Sclerenchyma (SCL), parenchyma bundle sheath (PBS) and mesophyll (MES) proportions (\% of transversal section) in leaf blades, according to species and level of insertion

\begin{tabular}{|c|c|c|c|}
\hline \multirow[b]{2}{*}{$\begin{array}{l}\text { Nível de inserção } \\
\text { Level of insertion }\end{array}$} & \multicolumn{3}{|c|}{$\begin{array}{l}\text { Espécie } \\
\text { Species }\end{array}$} \\
\hline & $\begin{array}{c}\text { Capim-braquiária } \\
\text { Signalgrass }\end{array}$ & $\begin{array}{c}\text { Capim-gordura } \\
\text { Molassesgrass }\end{array}$ & $\begin{array}{c}\text { Capim-tifton } 85 \\
\text { Bermudagrass tifton } 85\end{array}$ \\
\hline & \multicolumn{3}{|c|}{$\mathrm{ESC}(S C L)$} \\
\hline Inferior (Lower) & $0,83^{\mathrm{Ab}}$ & $0,86^{\mathrm{Bb}}$ & $2,30^{\mathrm{Ba}}$ \\
\hline Superior (Upper) & $1,00^{\mathrm{Ab}}$ & $1,42^{\mathrm{Ab}}$ & $2,86^{\mathrm{Aa}}$ \\
\hline & \multicolumn{3}{|c|}{$\mathrm{BPF}(P B S)$} \\
\hline Inferior (Lower) & $28,7^{\mathrm{Ba}}$ & $27,0^{\mathrm{Ba}}$ & $22,9^{\mathrm{Ab}}$ \\
\hline Superior (Upper) & $32,1^{\mathrm{Aa}}$ & $\begin{array}{c}33,2^{\mathrm{Aa}} \\
\text { MES }\end{array}$ & $22,1^{\mathrm{Ab}}$ \\
\hline Inferior (Lower) & $39,8^{\mathrm{Ab}}$ & $38,2^{\mathrm{Ab}}$ & $43,7^{\mathrm{Aa}}$ \\
\hline Superior (Upper) & $35,8^{\mathrm{Bb}}$ & $29,7^{\mathrm{Bc}}$ & $41,4^{\mathrm{Aa}}$ \\
\hline
\end{tabular}

Médias seguidas de letras diferentes, minúsculas nas linhas e maiúsculas nas colunas, em cada tecido, diferem $(P<0,05)$ pelo teste de Tukey.

Means followed by different letters, small in the row and capital in the column, for each tissue, are different (P<.05) by Tukey test.

R. Bras. Zootec., v.31, n.2, p.890-899, 2002 (suplemento) 
inserção da folha no perfilho. Estes dados são consistentes com os relatos de Wilson (1976b), que evidenciam um gradiente nas proporções dos tecidos da folha ao longo do perfilho de Panicum maximum var. trichoglume. Com base nos resultados obtidos em condições controladas de ambiente, esse autor sugeriu que a variação na anatomia da folha com o nível de inserção é um fenômeno inerente ao desenvolvimento do perfilho e, provavelmente, se expresse em grande parte das gramíneas.

Lâminas foliares do topo do perfilho sendo mais longas (Gomide, 1997; Queiroz, 1997) necessitam de forte suporte estrutural para manter sua conformação ereta, sendo este suporte formado, principalmente, pelo XIL e pelo ESC associado. Assim, as percentagens de ESC e XIL na seção transversal da lâmina foliar mostram altas correlações $(r=0,93$ e 0,95 , respectivamente) com o tamanho da folha (Wilson, 1976b). Tais tecidos são resistentes à digestão, o que explica, em parte, a menor digestibilidade de lâminas de mais altos níveis de inserção, quando comparadas em uma mesma idade, com lâminas da base do perfilho (Wilson, 1976a; Paciullo et al., 2001).

A espessura da parede de células do ESC aumentou $(\mathrm{P}<0,01)$ com o avanço da idade e foi maior, em geral, na estação do verão (Tabela 7 e Figura 2), embora só tenha sido observada significância para efeito de estação em fragmentos de colmo de capim-braquiária e capim-tifton 85 em idade avançada. Considerando o avanço na idade do colmo de 20 dias e a média dos valores das duas estações (verão e outono), verificase que o aumento na espessura da parede celular e as taxas de espessamento foram, respectivamente, de $1,83 \mu \mathrm{m}$ e $0,09 \mu \mathrm{m} /$ dia para capim-braquiária, $1,23 \mu \mathrm{m}$ e $0,06 \mu \mathrm{m} /$ dia para capim-gordura e $1,20 \mu \mathrm{m}$ e $0,06 \mu \mathrm{m} /$ dia para capim-tifton 85. A espessura da parede dos vasos de MET (Tabela 7) aumentou $(\mathrm{P}<0,05)$ com a idade, porém os incrementos de 0,22 ; 0,46 ; e $0,11 \mu \mathrm{m}$, respectivamente, para capimbraquiária, capim-gordura e capim-tifton 85 , foram substancialmente menores que os observados em células do ESC.

A utilização da coloração quádrupla triarca permitiu detectar a presença de sítios de lignificação na parede celular. Com o avanço do desenvolvimento, observaram-se no ESC, além dos aumentos na espessura da parede celular, incrementos na lignificação, principalmente no verão.

Lâminas recém-expandidas de capim-braquiária apresentaram maior $(\mathrm{P}<0,05)$ espessura da parede das células do esclerênquima, enquanto, em lâminas com 20 dias de idade, não se observou diferença entre as espécies (Tabela 8). A espessura da parede em células do ESC aumentou ( $\mathrm{P}<0,05)$ com a idade em capim-tifton 85 e capim-gordura, não se alterando, contudo, em capim-braquiária.

Lâminas do nível de inserção superior do perfilho apresentaram paredes celulares mais espessas $(\mathrm{P}<0,05)$ que lâminas da base. Os valores foram de 2,01 e $1,41 \mu \mathrm{m}$, para espessura das paredes do ESC,

Tabela 7 - Espessura da parede $(\mu \mathrm{m})$ das células do esclerênquima (ESC) e de vasos de metaxilema (MET) em fragmentos de colmo, conforme a idade, a estação de crescimento e a espécie

Table 7 - Cell wall thickness $(\mu \mathrm{m})$ of sclerenchyma (SCL) and metaxilem vessels (MET) in stem fragments, according to age, season of growth and species

\begin{tabular}{|c|c|c|c|c|}
\hline \multirow[b]{2}{*}{$\begin{array}{l}\text { Idade } \\
\text { Age }\end{array}$} & \multirow[b]{2}{*}{$\begin{array}{c}\text { Estação de crescimento } \\
\text { Season of growth }\end{array}$} & \multicolumn{3}{|c|}{$\begin{array}{l}\text { Espécie } \\
\text { Species }\end{array}$} \\
\hline & & $\begin{array}{c}\text { Capim-braquiária } \\
\text { Signalgrass }\end{array}$ & $\begin{array}{l}\text { Capim-gordura } \\
\text { Molassesgrass }\end{array}$ & $\begin{array}{c}\text { Capim-tifton } 85 \\
\text { Bermudagrass tifton } 85\end{array}$ \\
\hline & & & $\mathrm{ESC}(S C L)$ & \\
\hline Jovem & Verão (Summer) & $1,43^{\mathrm{Aa}}$ & $0,89^{\mathrm{Ab}}$ & $1,28^{\mathrm{Aa}}$ \\
\hline Young & Outono (Autumn) & $1,29 \mathrm{Aa}$ & $0,63^{\mathrm{Ab}}$ & $1,07^{\mathrm{Aa}}$ \\
\hline Avançada & Verão (Summer) & $3,74^{\mathrm{Aa}}$ & $2,08^{\mathrm{Ac}}$ & $2,72^{\mathrm{Ab}}$ \\
\hline Old & Outono (Autumn) & $2,64^{\mathrm{Ba}}$ & $1,90^{\mathrm{Ab}}$ & $2,03^{\mathrm{Bb}}$ \\
\hline & & & MET & \\
\hline Jovem & - & $1,71^{\mathrm{Ba}}$ & $1,31^{\mathrm{Bb}}$ & $1,54^{\mathrm{Aa}}$ \\
\hline $\begin{array}{l}\text { Young } \\
\text { Avançada }\end{array}$ & - & $1,93^{\mathrm{Aa}}$ & $1,77^{\mathrm{Aab}}$ & $1,65^{\mathrm{Ab}}$ \\
\hline
\end{tabular}

Médias seguidas de letras diferentes, minúsculas nas linhas comparam espécies e maiúsculas nas colunas, em cada tecido, diferem $(\mathrm{P}<0,05)$ pelo teste de Tukey.

Means followed by different letters, small in the row compare species, and capital in the column, for each tissue, are different (P<.05) by Tukey test. 

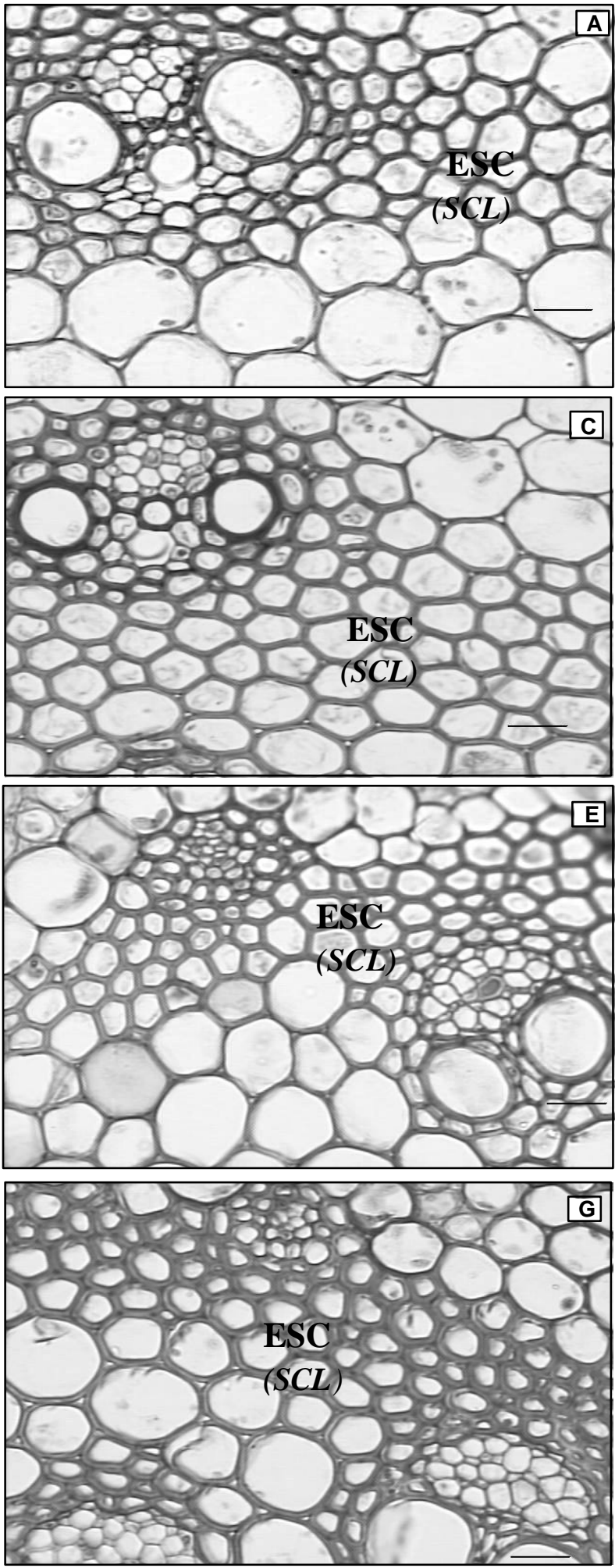
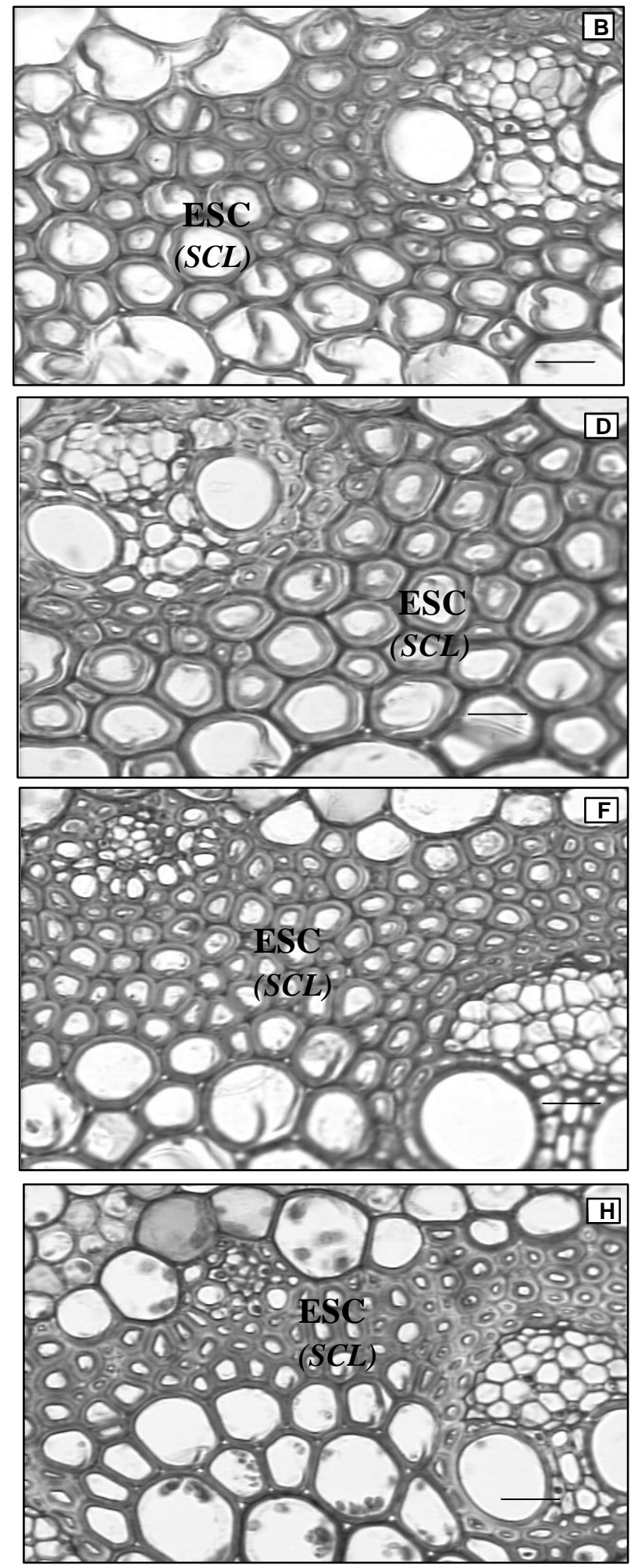

Figura 2 - Seções transversais de fragmentos de colmo mostrando aumento da espessura da parede de células do esclerênquima (ESC). (A) e (C) colmo jovem de capim-braquiária no outono e verão, respectivamente; (B) e (D) colmo em idade avançada de capim-braquiária no outono e verão, respectivamente; $(E)$ e $(G)$ colmo jovem de capim-tifton 85 no outono e verão, respectivamente e $(F)$ e $(\mathrm{H})$ colmo em idade avançada de capim-tifton 85 no outono e verão, respectivamente. ( $-15 \mu \mathrm{m})$.

Figure 2 - Transversal sections of stem fragments showing increase of sclerenchyma (SCL) cell wall thickness. (A) and (C) young stem of signalgrass in autumn and summer, respectively; $(B)$ and $(D)$ old stem of signalgrass in autumn and summer, respectively; $(E)$ and $(G)$ young stem of bermudagrass Tifton 85 in autumn and summer, respectively and $(F)$ and $(H)$ old stem of bermudagrass Tifton 85 in autumn and summer, respectively. ( $15 \mu \mathrm{m})$. 
Tabela 8 - Espessura da parede $(\mu \mathrm{m})$ de células do esclerênquima de lâminas foliares, conforme a idade e a espécie Table 8 - Sclerenchyma cell wall thickness $(\mu \mathrm{m})$ in leaf blades, according to age and species

\begin{tabular}{lccc}
\hline & & $\begin{array}{c}\text { Espécie } \\
\text { Species }\end{array}$ & \\
\cline { 2 - 4 } Idade (dias) & Capim-gordura & Capim-tifton 85 \\
Age (days) & Molassesgrass & Bermudagrass tifton 85 \\
\hline 0 & $1,73^{\mathrm{Aa}}$ & $1,56^{\mathrm{Bb}}$ & $1,62^{\mathrm{Bab}}$ \\
20 & $1,78^{\mathrm{Aa}}$ & $1,76^{\mathrm{Aa}}$ & $1,80^{\mathrm{Aa}}$ \\
\hline
\end{tabular}

Médias seguidas de letras diferentes, minúsculas nas linhas e maiúsculas nas colunas, diferem $(P<0,05)$ pelo teste de Tukey.

Means followed by different letters, small in the row and capital in the column, are different $(P<.05)$ by Tukey test.

e de 1,30 e 1,06 $\mu \mathrm{m}$, para espessura das paredes do MET, respectivamente, para lâminas das posições superior e inferior do perfilho. Tal comportamento reforça a hipótese de que lâminas do nível de inserção superior, por serem mais longas, apresentam estrutura de suporte mais desenvolvida, com maior proporção de tecidos de sustentação (ESC e XIL) e paredes celulares mais espessas.

As diferenças na anatomia das espécies avaliadas sugerem variações na qualidade das gramíneas. A grande diversidade de espécies forrageiras utilizadas em sistemas de exploração de bovinos evidencia a possibilidade de avaliações das características anatômicas, não somente para estimação do valor nutricional de forrageiras, mas também para orientação em trabalhos de melhoramento genético. Wilson (1997) sugere a possibilidade de seleção de espécies forrageiras baseada em algumas características anatômicas, tais como freqüência de estrutura "girder" na lâmina foliar, proporção de ESC, espessura da parede celular, sinuosidade das paredes de células da epiderme, entre outras. Tais características anatômicas podem ser trabalhadas em programas de melhoramento, visando obtenção de gramíneas forrageiras de melhor qualidade.

\section{Conclusões}

A proporção de tecidos da lâmina foliar não variou após sua completa expansão, mas a anatomia do colmo alterou-se em função de sua idade.

Lâminas foliares de mais alto nível de inserção apresentaram maior porcentagem de tecidos de sustentação e células com paredes mais espessas que lâminas da base do perfilho.

Segmentos de colmos apresentaram maior porcentagem de esclerênquima e paredes celulares mais espessas no verão.

\section{Literatura Citada}

AKIN, D.E. Histological and physical factors affecting digestibility of forages. Agronomy of Journal, v.81, n.1, p.17-25, 1989.

AKIN, D.E.; AMOS, H.E.; BARTON, F.E. et al. Rumen microbial degradation of grass tissue by scanning electron microscopy. Agronomy of Journal, v.65, n.5, p.825-828, 1973.

CHESSON, A.; STEWART, C.S.; DALGARNO et al. Degradation of isolated grass mesophyll, epidermis and fibre cell wall in the rumen and by cellulolitic rumen bacteria in axemic culture. Journal Applied Bacteriology, v.60, n.4, p.327-336, 1986.

GOMIDE, C.A.M. Morfogênese e análise de crescimento de quatro cultivares de Panicum maximum cultivadas em vaso. Viçosa-MG: Universidade Federal de Viçosa, 1997. 53p. Dissertação (Mestrado em Zootecnia) - Universidade Federal de Viçosa, 1997.

HACKER, J.B.; MINSON, D.J. The digestibility of plant parts. Herbage Abstracts, v.51, n.9, p.459-482, 1981.

HAGQUIST, C.W. Preparation and care of microscope slides. American Biology Teacher, v.36, p.414-417, 1974.

PACIULLO, D.S.C.; MATTOS, J.L.S.; GOMIDE, J.A. et al. 1999. Proporção de tecidos e espessura da parede celular em espécies de braquiária, cultivadas sob diferentes níveis de umidade no solo. In: REUNIÃO ANUAL DA SOCIEDADE BRASILEIRA DE ZOOTECNIA, 36., 1999, Porto Alegre. Anais...São Paulo: Sociedade Brasileira de Zootecnia/Gmosis, [1999]. CD-ROM. Forragicultura.

PACIULLO, D.S.C.; GOMIDE, J.A.; QUEIROZ, D.S. et al. Composição química e digestibilidade "in vitro" de lâminas foliares e colmos de gramíneas forrageiras, em função do nível de inserção no perfilho, da idade e da estação de crescimento. Revista Brasileira de Zootecnia, v.30, n.3, S.1, p.964-974, 2001.

QUEIROZ, D.S. Características anatômicas, químicas e digestibilidade in vitro de três gramíneas forrageiras. Viçosa, MG: Universidade Federal de Viçosa, 1997. 90p. Tese (Doutorado em Zootecnia) - Universidade Federal de Viçosa, 1997.

QUEIROZ, D.S.; GOMIDE, J.A.; MARIA, J. Avaliação da folha e do colmo de topo e base de perfilhos de três gramíneas forrageiras. 2. Anatomia. Revista Brasileira de Zootecnia v. 29, n. 1, p.61-68, 2000.

UNIVERSIDADE FEDERAL DE VIÇOSA - UFV. SAEG. Sistemas de Análises Estatísticas e genética. Viçosa, MG: 1995. (Apostila) 
WILKINS, R.J. The potential digestibility of cellulose in grasses and its relationships with chemical and anatomical parameters. Journal of Animal Science, v.78, n.3, p.457-464, 1972.

WILSON, J.R. Variation of leaf characteristics with level of insertion on a grass tiller. I. Development rate, chemical composition, and dry matter digestibility. Australian Journal of Agriculture Research, v.27, n.3, p.343-354, 1976a.

WILSON, J.R. Variation of leaf characteristics with level of insertion on a grass tiller. II. Anatomy.Australian Journal of Agriculture Research, v.27, n.3, p.355-364, 1976 b.

WILSON, J.R. Organization of forage plant tissues. In: JUNG, H.G.; BUXTON, D.R.; HATFIELD, R.D. (Eds.) et al. Forage cell wall structure and digestibility. Madison: American Society of Agronomy, Crop Science Society of America, Soil Science Society of America, 1993. p.1-32.

WILSON, J.R. Strutural and anatomical traits of forages influencing their nutritive value for ruminants. In: SIMPÓSIO INTERNACIONAL SOBRE PRODUÇÃO ANIMAL EM PASTEJO, 1997, Viçosa, MG. Anais... Viçosa, MG: Universidade Federal de Viçosa, 1997. p.173-208.
WILSON, J.R.; DEINUM, B.; ENGELS, F.M. Temperature effects on anatomy and digestibility of leaf and stem of tropical and temperate forage species. Netherlands Journal of Agriculture Science, v.39, n.1, p.31-48, 1991.

WILSON, J.R.; MERTENS, D.R.; HATFIELD, R.D. Isolates of cell types from sorghum stems: digestion, cell wall and anatomical characteristics. Journal Science Food Agriculture, v.63, p.407-417, 1993.

Recebido em: 25/05/01

Aceito em: 11/12/01 